\title{
Uma abordagem fenomenológico-existencial para a questão do conhecimento em psicologia
}

\author{
Marcelo Vial Roehe \\ Universidade Regional Integrada do Alto Uruguai e das Missões
}

\begin{abstract}
Resumo
Partindo da analítica existencial do filósofo Martin Heidegger, o artigo propõe que o conhecimento é um correlato ontológico do modo de ser humano e que a tradição científica comete um erro ontológico quando, por meio de uma suposta assepsia metodológica, separa o conhecedor do conhecido. Sendo assim, argumenta-se que qualquer empreendimento científico está vinculado às características do ser humano, que qualquer que seja o foco de uma investigação científica, este já estará sempre submetido às possibilidades perspectivas humanas. Portanto, a objetividade que a tradição científica preconiza, de modo algum se realiza. Propõe-se também que a psicologia não necessita adotar o modelo naturalista tradicional, a fim de adquirir credibilidade científica.
\end{abstract}

Palavras-chave: fenomenologia-existencial; heidegger; conhecimento psicológico

\begin{abstract}
An existential-phenomenological approach to the problem of psychological knowledge. Based on German philosopher Martin Heidegger's existential analytic, this article proposes that knowledge is an ontological counterpart to man's mode of being, and the scientific tradition incurs in ontological error when, through the use of a so-called methodological asepsis, it separates who-knows (the "subject” of knowledge) from whatis-known (the "object” of knowledge). Thus, it can be argued that any scientific enterprise is linked to the characteristics of human beings, and whatever focus a scientific investigation might have, this focus will always be limited by human perceptive capabilities and, therefore, the objectivity proclaimed by the scientific tradition is never achieved at all. The article also proposes that psychology does not need to adopt the traditional naturalistic model in order to achieve scientific credibility.
\end{abstract}

Keywords: existential-phenomenology; heidegger; psychological knowledge.

A questão do conhecimento será aqui abordada a partir da analítica existencial do filósofo alemão Martin Heidegger (1889-1976). A analítica, publicada na obra Ser e Tempo, em 1927, veio a ser a base para o desenvolvimento da chamada psicologia fenomenológico-existencial. Heidegger estudou e trabalhou cerca de 10 com Edmund Husserl (1859-1938), o fundador da Fenomenologia. Ser e Tempo une o pensamento e o procedimento fenomenológicos com o questionamento do modo de ser humano. É nessa obra que aparecem termos como existência e existencial, que viriam a se tornar tradicionais na filosofia e na psicologia, principalmente em virtude do movimento existencialista, popularizado por Jean Paul Sartre (1905-1980).

Fenomenologia é definida por King (2001) como "o estudo das formas como algo aparece ou se manifesta, em contraste com estudos que procuram explicar as coisas a partir de relações causais ou processos evolutivos” (p. 109). A forma como algo se manifesta é o que se chama de fenômeno.
Para Husserl, os fenômenos são acessíveis pela intencionalidade que caracteriza a consciência humana, ao passo que, para Heidegger, os fenômenos são acessíveis pelo modo humano de ser, modo este que abrange mais do que o aspecto cognitivo-intencional.

Historicamente, o problema do conhecimento parece ser diferenciar os objetos que, supostamente, conhecemos daquilo que nós mesmos somos, visto que nossa percepção poderia distorcer a realidade daquilo que se pretende conhecer. Tem-se, portanto, a necessidade de estabelecer rigidamente a "fronteira" entre o conhecedor e o conhecido.

Edmund Husserl (1990) elaborou a Fenomenologia questionando, por exemplo, "como pode o conhecimento estar certo de sua consonância com as coisas que existem em si, de as ‘atingir'?” (p. 21).

Muito antes de Husserl, no século XVII, questionamentos similares já estavam nas origens do método científico, com o racionalismo de Descartes e o empirismo de Bacon. 
Ao método caberia garantir a assepsia do conhecimento ante, conforme Figueiredo (1995), às tendências anticientíficas do homem, ante a sensibilidade idiossincrática, ilusória e efêmera que "bloqueia ou deforma a leitura do livro objetivo da natureza" (Figueiredo, 1995, p. 15).

Assim sendo, tem-se a seguinte situação: o conhecedor (“de um lado”) que dispõe de um método (o qual elimina do procedimento a sua sensibilidade) para atingir o conhecido (“do outro lado”). Em síntese, esse é o estilo científiconaturalista de produzir conhecimento. É a herança do dualismo cartesiano que, inflando o sujeito com a racionalidade, fez-lhe limitado em sua existencialidade. Pois, seria como se o conhecimento fosse um empreendimento distinto do homem, como se fosse um ponto isolado, que o pesquisador atingiria após despojar-se de sua humanidade viesada, de sua sensibilidade.

A abordagem fenomenológico-existencial vai mostrar que: (I) qualquer procedimento científico está vinculado ao modo de ser do homem; (II) a psicologia não necessita adotar o modelo naturalista para suas investigações; e (III) as ciências naturais não realizam a desejada assepsia metodológica.

\section{I}

Husserl inicia o questionamento fenomenológico pela consciência intencional: o pensar é sempre o pensar em algo, o “objeto” a ser conhecido somente o será já capturado pela intencionalidade que caracteriza qualquer cognição. Antes de qualquer procedimento científico, uma unidade intencional conhecedor-método-conhecimento já terá desfeito qualquer pretensa "pureza” epistemológica. Husserl considera a consciência o fundamento da realidade, visto que ocupa uma posição de prioridade ontológica (Jennings, 1986). Quer dizer, assim como a consciência apresenta-se na forma de um tipo específico de ser entre outros - podendo ser objeto para si mesma -, ela também possibilita a percepção de todos os demais seres possíveis.

Todavia, será Heidegger (1927/1993) quem vai levar a consciência intencional husserliana além das fronteiras mentalistas: antes da consciência intencional há um modo de ser que a possibilita. Este é o modo de ser do homem, retomado por Heidegger em oposição à tradição metafísica do “animal racional”. O filósofo chama Dasein ao modo humano de ser. O Dasein é o ente que, sendo, des-cobre, revela o Ser (o quê e como algo é) em geral, porque tem uma compreensão do Ser, ainda que não explicitada e/ou elaborada. É sendo des-cobridor que o Dasein conhece. Pode-se dizer que o Dasein está sempre conhecendo, ele é conhecendo. Assim sendo, a pureza epistêmico-metodológica naturalista é impossível.

Stein (1990) traduz Dasein por Estar-aí. Entretanto, internacionalmente, já é corrente a manutenção do original alemão; como este texto não está no domínio da Filosofia, porém no da Psicologia, vai-se manter a designação ser humano para expressar, contudo, a envergadura do Dasein.

O Dasein, como o modo humano de ser, tem uma compreensão do ser, ele compreende o ser dos demais entes (os que não são Dasein), assim como compreende seu próprio ser, tem uma relação com seu próprio ser. Em função de compreender o ser, o ser humano é ontológico. Essa compreensão, em geral vaga, mediana, informal ocorre em meio aos demais entes com os quais o ser humano se relaciona, em meio aos quais ele sempre está e com os quais se identifica, na maioria das vezes. Em função de estar (ser) em meio aos demais entes e identificar-se com eles numa cotidianidade mediana, o ser humano é ôntico (Heidegger, 1927/1993).

O ser-ontológico do homem é ser o lugar (o aî) da des-coberta e do encontro com todos os demais entes. O ser-ôntico do homem é já estar sempre em meio a esses entes, identificado com eles, como se fosse mais um entre outros, vivendo sua vida como fulano que tem um jeito de ser particular.

Em sua obra Ser e Tempo, Heidegger se propôs a elaborar uma ontologia fundamental. Num vocabulário simplificado pode-se dizer que o filósofo pretendia mostrar aonde e como tudo começa. Tudo o quê? Tudo que é. O que é inicia no modo humano de ser, o qual se diferencia dos demais modos de ser por ter uma compreensão do ser. É a partir da compreensão do ser - informal, não intelectualizada - que o homem desenvolve o conhecimento que, por sua vez, também não é necessariamente intelectualizado, culto, formalmente reconhecido. O conhecimento poderá, sim, ser formalmente elaborado de modo sistemático, metodológico, crítico e geral constituindo, então, conhecimento científico (Giorgi, 1995). O status científico, no entanto, de modo algum dissocia o conhecedor do conhecido: "Como atitude do homem, as ciências possuem o modo de ser desse ente (homem)" (Heidegger, 1927/1993, p. 38).

É importante ressaltar: do modo de ser humano dependem os demais entes para aparecer, entretanto, essa aparição não se reduz a uma idealização. Os objetos (entes) do conhecimento são distintos do ser humano, são distintos do ato conhecedor, porém dependem dele para ser; aquilo que transcende o conhecimento, aquilo que o conhecimento dá a conhecer somente se faz presente em função do modo de ser descobridor, revelador, compreensivo - do homem.

Na tradição ocidental, o conhecimento inicia na distinção sujeito-objeto. O sujeito atinge o objeto na forma de representações (mentais) racionalmente purificadas. Em Heidegger (1927/1993), o ser humano já está junto aos objetos que, por sua vez, não são coisas extensas, mas sim constituem o Mundo, na forma das diferentes relações que o ser humano estabelece com as coisas. Exemplo: uma barra de giz não se mostra como matéria extensa; uma barra de giz recebe sentido como um instrumento que permite ao ser humano que se comunique de uma certa maneira, maneira esta adequada ao local em que se dá a comunicação e adequada ao encontro típico com outros seres humanos que se dá nesse local. A barra de giz estará sempre referida ao modo de ser humano: sendo como é, o ser humano produz barras de giz.

Sujeito-objeto é uma distinção que somente pode ser feita quando se rompe a unidade Ser-no-mundo que caracteriza, ontologicamente, o ser humano. 
É a partir do ser-em que se estabelece a receptividade e a espontaneidade da experiência (...) É assim que o ser-em do ser-no-mundo torna-se o momento indepassável, o transcendente à consciência que funda o conhecimento. Mas esse fundar não é mais fundamento como na metafísica, que dissocia o fundante do fundado e dá ao primeiro um caráter a priori, de primeiro, de originário, de presença constante (Stein, 2000, p. 114).

Por Metafísica entenda-se a tradição majoritária do pensamento ocidental no que diz respeito ao questionamento da realidade. Tal tradição abarca diferentes modos de pensamento, todos presentes na história da Psicologia: Naturalismo, Cartesianismo, Positivismo, Racionalismo.

O caminho da Metafísica, conforme Critelli (1996), inicia com a proposição do conceito por Platão. No conceito a verdade se manifesta de forma única e imutável. A seguir, Aristóteles determina que o intelecto é o responsável pelo conhecimento (conceitos) e, por fim, Descartes recoloca o intelecto como Cogito, "um ponto de segurança para o pensar” (Critelli, 1996, p. 13).

A analítica existencial de Heidegger permite questionar qualquer ponto seguro para o conhecimento, que não leve em consideração a ontologia fundamental do modo de ser humano: estes serão arbitrários e artificiais, caso não iniciem com o momento primeiro, as vicissitudes do ser-no-mundo.

Já sempre no-mundo, o ser humano é receptivo aos encontros incessantes com os demais entes a partir do seu Humor e da sua Compreensão (Heidegger, 1927/1993).

O humor indica como alguém está, como vai. O humor influencia naquilo que se percebe e como se percebe: podese estar atento a muitas coisas ou a poucas, acessível a determinados temas e desligado de outros, sensível a alguns objetos e pessoas e insensível a outros. O ser humano entra em sintonia com aquilo que mais se aproxima do seu humor.

O humor diz respeito ao que em Psicologia, tradicionalmente, se chama de sentimento, emoção ou afeto.

O principal para o propósito deste texto é: o ser humano sempre está num determinado humor. Portanto, não há como sustentar o primado da racionalidade para o conhecimento. A precisão metodológica ou a razão clara e distinta são já manifestação de um humor específico (talvez um humor científico?).

Além disso, o ser humano sempre já se orienta numa determinada compreensão do seu contexto, numa familiaridade para consigo e para com o que lhe é próximo (Heidegger, 1927/1993). Isto não quer dizer que se trata de uma compreensão intelectualizada, bem informada, estudada ou um conhecimento claro; não, a compreensão se refere a já estar junto a um conjunto de entes humanos e não-humanos que constituem o seu cotidiano médio. É a partir dessa compreensão vaga, mediana, não-teorizada - que se pode desenvolver o conhecimento formal.

A compreensão envolve sempre uma posição prévia, uma visão prévia e uma concepção prévia.

Posição prévia é o contexto no qual o ser humano já sempre está e com o qual já sempre se relaciona, desenvolvendo uma compreensão característica desse contexto.
Visão prévia diz respeito ao parâmetro ou critério em função do qual o que será compreendido é ressaltado do contexto. Heidegger (1927/1993) fala em desentranhamento e recorte do compreendido de seu contexto habitual.

Concepção prévia refere-se às conceituações relativas ao recortado que já sempre estão presentes em qualquer investida compreensiva.

Portanto, qualquer empreendimento científico sempre se dará num contexto típico no qual se elegerá uma prioridade a ser abordada e realçada do contexto, tendo em vista conceitos ou idéias já presentes sobre o que será investigado. Vejase um exemplo para a Psicologia: posição prévia - o modelo científico clássico, estruturado físico-matematicamente, a fim de gerar informação que deve ser universal para ser válida; visão prévia - o estatuto científico da Psicologia assegurado pela aplicação do modelo científico clássico; concepção prévia - a elaboração de inventários escalares de personalidade.

\section{II}

A Psicologia, a fim de emancipar-se da Filosofia e adquirir status científico, no final do século XIX, assumiu como seus os objetivos da Ciência (Natural) então praticada. Em seus primórdios, a Psicologia científica necessitava do aval de posições tradicionais do conhecimento - ainda que na forma de cópia - para obter relevância.

O interessante é que de modo algum houve a propalada restrição da sensibilidade, uma vez que a formalização do conhecimento como Ciência é uma possibilidade do modo de ser humano. Estude-se o clima típico de uma região ou o porquê das pessoas terem dificuldade de dizer o que querem dizer em determinadas ocasiões, estar-se-á sempre no domínio do humor e da compreensão.

A distinção entre ciências naturais e ciências humanas, anterior a Heidegger, se por um lado realçava o desconforto com a concepção cientifica clássica, no que diz respeito aos seus estudos sobre o homem, por outro lado deixava entender (e ainda deixa) que nas humanas a sensibilidade era liberta da amarra metodológica e que o conhecimento obtido estava autorizado a ser impreciso, ao passo que nas naturais o legado físico-matemático estava preservado, na forma de conhecimento exato, preciso.

Pois bem, o que se escreveu até aqui permite afirmar: somente existe ciência humana.

E se assim é, que se fale apenas em ciência.

Ciência é um conjunto de procedimentos elaborados pelo homem, a fim de desenvolver conhecimento formal, de modo a qualificar aquilo que medianamente, vagamente, informalmente, intuitivamente já se compreende. O que não significa afirmar que esta compreensão do senso comum seja superada ou deixada de lado. São poucos os cientistas entre os homens.

Talvez nenhuma outra área do conhecimento debata tanto sua cientificidade como a Psicologia. Talvez porque nenhuma outra área do conhecimento se distancie tanto do sujeito e do objeto da tradição como a Psicologia. E porque, talvez, a Psicologia seja a área do conhecimento menos infor- 
mada a respeito daquilo que estuda. E também porque, talvez, a Psicologia estude o mais complexo dos objetos: aquele que nunca é objeto. E ainda mais: talvez porque a Psicologia seja a melhor das ciências demonstrando, conforme defende Heidegger (1927/1993), “sua capacidade de sofrer uma crise em seus conceitos fundamentais” (p. 35).

Em tais crises, o que se questiona é o vínculo das investigações com aquilo que é investigado. O que é a coisa mesma que a ciência psicológica estuda? O aparato epistêmicometodológico da Psicologia permite que seu investigado se mostre tal como é? A essas questões não se dará respostas cabais, do contrário a possibilidade das crises de fundamento poderá ser dificultada, falseando, ainda mais, o modo de ser humano-científico, o qual duvida, regride para avançar, desfaz para refazer.

Seguem-se pistas heideggerianas:

O rigor da ciência matemática é a exatidão... Ao contrário todas as ciências do espírito e até todas as ciências do ser vivo para permanecerem rigorosas, precisam justamente ser inexatas. Pode-se, de fato, apreender também o ser vivo como uma grandeza espácio-temporal do movimento, mas nesse caso não se apreende mais o vivente. (Heidegger, citado em Luijpen, 1973, p. 174, nota 348)

O modo psicológico de expressão humana, o ser-psicológico do homem não é uma grandeza espácio-temporal, portanto uma investigação orientada pela exatidão tenderá a encontrar um simulacro.

A exatidão, a certeza são modos humanos de orientar investigações, entretanto aquilo que é investigado deve ter seu próprio modo de ser reconhecido, a fim de que se possa - exatamente - obter informações sobre ele. A exatidão e a precisão não estão no método, porém no reconhecimento do estatuto ontológico dos constituintes do processo científico.

"Heidegger, na busca do ponto de partida do conhecimento, estabelece como elemento inicial, o ser-em do ser-nomundo que é o modo como o Dasein desde sempre se dá" (Stein, 2000, p. 110).

O ser-em abrange Humor e Compreensão. Logo, as diversas áreas de investigação científica têm seu início quando o Dasein (construto neutro) se manifesta de maneira ôntica (sendo fulano ou beltrano), vivendo num determinado lugar, interessado nessas ou naquelas questões, querendo saber mais para poder transformar algo relativo ao seu contexto de vida).

Quando o questionamento do ser humano se volta para si mesmo tem-se o que, tradicionalmente, se chama de uma ciência humana. Aqui não é, apenas, questão de reconhecer que o ponto de partida é o modo de ser humano. Este mesmo modo de ser se dará como questionador e como questionado. Já se movendo num determinado humor e numa determinada compreensão o ser humano procurará investigar este mesmo modo de ser (humorado e compreensivo). Estabelecer-se-á, então, uma relação circular: humorado e compreensivo o homem investiga a si próprio em seus humores e compreensões e des-co-bre-se já sempre num humor e numa compreensão que lhe "guiam" a busca cognoscitiva, já sempre humorada e compreensiva.

Se, como afirma Heidegger (1927/1993), a ciência tem o modo de ser do Dasein, as ciências que investigam o ser humano se voltam sobre si mesmas, num exercício de autoinvestigação da sua própria possibilidade científica, ou seja, o modo humano de ser.

Qual o ponto de partida da Psicologia? O modo de ser humano como tal (ontológico) que é a condição para os fenômenos (ônticos) psicológicos. Possivelmente, para a ciência psicológica seja mais produtivo ter clara a origem (ontológica) de seus fenômenos típicos, uma vez que os fenômenos psicológicos propriamente ditos parecem já razoavelmente conhecidos. Ou seja, os fenômenos psicológicos são comportamentais, são mentais, são emocionais ou linguísticonarrativos, construtivos? Provavelmente nem um, nem outro, mas sim todos, uma unidade de todos os citados acima. Essa unidade, no entanto, permanece inacessível, e a psicologia segue com seus debates parcializados, escolarizados. Pergunta-se: como é o homem, de modo que pode manifestar e reconhecer fenômenos psicológicos?

Sabendo-se como é o ser humano (nível ontológico) dever-se-á poder identificar o percurso do nível ontológico para o ôntico-psicológico. Ampliando a idéia; como o ser humano, entendido onto-filosoficamente (via descrição fenomenológica) se psicologiza, se sociologiza, se antropologiza, se teologiza...?

Qualquer fenômeno humano deve sempre estar referido à sua estrutura ontológica (Dasein).

\section{III}

O que se desenvolveu até aqui facilita em muito a reflexão sobre este terceiro ponto: a ciência clássica (natural ou exata) com sua epistemologia físico-matemática não excluiu e nem poderia excluir o nível fenomênico ou a sensibilidade do empreendimento científico.

Stein (1990) cita texto de Heidegger de 1925: "Conhecimento do mundo é um modo de ser do estar-aí (o ser humano) e um modo de ser que está onticamente fundado em sua constituição fundamental, o ser-no-mundo” (p. 25). Mais adiante se encontra: “conhecimento é sempre um modo de ser do estar-aí na base de seu já-estar-junto-do-mundo” (Heidegger, citado por Stein, 1990, p. 26).

Há algo de humano em qualquer objeto conhecido, pois este somente aparece relativamente ao ser do homem - ao ser que conhece. Logo, o processamento formal do conhecimento afirma o ser do homem. Qualquer objeto visado afirma o ser do homem. O ideal científico de neutralidade do conhecedor ante o conhecido é inviável, uma vez que o último apenas se dá como tal relativamente ao ser do primeiro.

A analítica existencial de Heidegger, conduzida na tradição fenomenológica de Husserl, é um esforço metodológico que, neste texto, tenta-se entender da seguinte maneira: o ser humano olha o olhar e revela-o para si próprio como um ver que dá algo de si para o que é visto. 
Olhar o olhar é possível devido à circularidade que caracteriza o modo de ser humano. O homem compreende o ser e, por isso, compreende a si mesmo como sendo e, assim sendo, compreende o ser. Compreende o ser, porque compreende a si mesmo e compreende a si mesmo, porque compreende o ser (Heidegger, 1927/1993; Stein, 1983, 1990).

O que o ser humano dá de si é a condição para que algo seja visto. Sem o homem, nada seria visto. Contudo, esse ver não vê uma pura presença. Essa condição não é um espelhamento do que aparece. Aquilo que é visto, percebido, compreendido, manipulado somente o é já envolvido nas possibilidades do modo humano de ser. Já é percebido por um determinado humor, por uma determinada compreensão, por uma determinada estrutura prévia (ver acima).

Em sua conferência “Que é isto - a Filosofia?”, Heidegger (1999) afirma que:

Muitas vezes e quase por toda parte reina a idéia de que o pensamento que se guia pelo modelo da representação e cálculo puramente lógicos é absolutamente livre de qualquer disposição ${ }^{1}$. Mas também a frieza do cálculo, também a sobriedade prosaica da planificação são sinais de um tipo de dis-posição”. (p. 39)

Adiante, Heidegger escreve que mesmo a razão, supostamente livre das “paixões” está “pré-dis-posta para a confiança na evidência lógico-matemática de seus princípios e regras” (p. 39).

A referência que Heidegger (1999) faz a Descartes é suficiente para que se re-pense a epistemologia e a ciência clássicas: a dúvida cartesiana foi o humor que levou à certeza. Então, na base da epistemologia moderna, no fundamento da ciência há o que a Psicologia chama de sentimento, emoção ou afeto.

Desde seus primórdios, a Ciência reconhece, implicitamente, esta situação - que o homem vê dando algo de si para o que é visto. Observa-se isso na busca por eliminar dos procedimentos de investigação o nível fenomênico (Giorgi, 1970/1978), com a expectativa de visualizar realidades em si, situações não permeadas pelo envolvimento humano. Por quê? Porque a presença humana, fluida como é (temporal, emocional, histórica, social...), foi interpretada como sendo fonte de erros, falhas, desvios, empecilhos ao conhecimento. Nessas condições, a solução encontrada, a fim de se obter resultados precisos, foi a exclusão - supostamente através do método - de qualquer aspecto experiencial no procedimento científico. Giorgi (1970/1978) apresentou a mais clássica exposição do quanto a Psicologia ficou empobrecida em virtude de tal abordagem.

Observado esse estado de coisas, pode-se afirmar que a neutralidade, a impessoalidade, o ascetismo científico-natural foi forjado a partir de um erro ontológico. A atitude científica clássica ignora a complexidade ontológica do homem. Não reconhece o papel do ser humano na constituição da realidade e, portanto, não considera adequadamente a presença do cientista numa investigação. Em resumo: não co- nhece o ser do homem, pois o trata como uma coisa diante de outra coisa. Por isso, erra.

Pretender excluir o nível fenomênico dos procedimentos científicos ou trabalhar supondo ser possível evitar referências à presença do pesquisador é o mesmo que separar o ato de conhecer do modo de ser humano. É a tentativa de subtrair ao homem uma faceta que lhe determina ontologicamente. Cria-se uma situação absurda: o pesquisador atua para conhecer, negando sua própria presença cognoscente. Assim, nenhum conhecimento seria possível. Se, fenomenologicamente, o homem vê dando algo de si para o que é visto, ou seja, sua condição ontológica, a compreensão de ser, a des-coberta; naturalisticamente, deveria ver sem sequer estar presente diante do que é visto. Se o homem é iluminando (deixando aparecer) o mundo, qualquer procedimento científico que exclua a presença humana apaga a luz, conseqüentemente nada poderia ser visto.

Investigue-se a qualidade do produto transgênico ou a vivência de quem sofre dor crônica, de modo algum se estará fora da alçada existencial ou além da popular subjetividade.

\begin{abstract}
A finalidade da pesquisa, portanto, não é mais o conhecimento dos átomos e de seu movimento "em si”, isto é, separados de nossa interrogação experiencial; antes, achamo-nos, desde o começo, no meio do ajuste de contas entre a natureza e o homem, de que a ciência natural constitui somente uma parte, de forma que a costumeira divisão do mundo em Sujeito e Objeto, mundo interior e mundo exterior, corpo e alma não mais se justifica e conduz a dificuldades. Logo, até na ciência natural o objeto da investigação não é mais a natureza em si, mas a natureza exposta à interrogação humana, encontrandose, portanto, aqui também o homem consigo mesmo. (Heisenberg, citado em Luijpen, 1973, p. 171, nota 333)
\end{abstract}

\section{Conclusão}

É a partir de tal concepção (existencial) do conhecimento que chamam a atenção expressões correntes em psicologia como bem-estar subjetivo (Albuquerque \& Troccoli, 2004), ou instrumento objetivo e, ainda, avaliação objetiva (Noronha, 2002). Há algum bem-estar que não seja aquele reconhecido por quem o vivencia? Há algum bem-estar cuja avaliação não tenha origem num sentimento de bem-estar de um pesquisador que tenha elaborado uma escala para avaliálo? E caso se aceitasse a terminologia em questão, haverá um bem-estar objetivo? Que deveria, logicamente, ser um bemestar sem sujeito?

Ainda que não se adote o referencial proposto neste artigo, é viável que profissionais de ensino e pesquisa mantenham uma postura epistemológica dessa natureza, claramente superada, e, com isso, todas as suas implicações? Ou, mais preocupante, repitam ingenuamente tais termos (subjetivo, objetivo e seus derivados) apropriados da tradição científica ou, até, do senso comum? Levando a pensar que não se qualificam no aspecto epistemológico? 
Espera-se que este artigo contribua para o debate epistemológico, através de um entendimento da questão do conhecimento que, orientado pela fenomenologia existencial de Heidegger, procura mostrar que é a partir do modo humano de ser que qualquer questão epistêmica adquire seu sentido original; de tal modo que o problema do conhecimento envolve uma discussão ontológica.

\section{Referências}

Albuquerque, A. S., \& Troccoli, B. T. (2004). Desenvolvimento de uma escala de bem-estar subjetivo. Psicologia: Teoria e Pesquisa, 20(2), 153-164.

Critelli, D. M. (1996). Analítica do sentido. São Paulo: Brasiliense.

Figueiredo, L. C. (1995). Matrizes do pensamento psicológico. Petrópolis: Vozes.

Giorgi, A. (1978). A psicologia como ciência humana (R. Schwartzman, Trad.). Belo Horizonte: Interlivros. (Originalmente publicado em 1970)

Giorgi, A. (1995). Phenomenological psychology. In J. Smith, R. Harré, \& L. Van Langenhove (Orgs.), Rethinking psychology (pp. 24-42). Londres: Sage.
Heidegger, M. (1993). Ser e tempo (M. Cavalcante, Trad.). Petrópolis: Vozes. (Originalmente publicado em 1927)

Heidegger, M. (1999). Conferências e escritos filosóficos (E. Stein, Trad.). São Paulo: Nova Cultural.

Jennings, J. L. (1986). Husserl revisited: the forgotten distinction between psychology and phenomenology. American Psychologist, 41(11), 1231-1240.

Husserl, E. (1990). A idéia da Fenomenologia (A. Mourão, Trad.). Lisboa: Edições 70

King, M. (2001). A guide to Heidegger's Being and Time. Albany: State University of New York.

Luijpen, W. (1973). Introdução à fenomenologia existencial (C. de Mattos, Trad.). São Paulo: EPU.

Noronha, A. P. P. (2002). Os problemas mais graves e mais freqüentes no uso dos testes psicológicos. Psicologia: Reflexão e Crítica, 15(1), 135-142.

Stein, E. (1983). A questão do método na filosofia: um estudo do modelo heideggeriano. Porto Alegre: Movimento.

Stein, E. (1990). Seis estudos sobre 'Ser e Tempo' (Martin Heidegger). Petrópolis: Vozes.

Stein, E. (2000). Diferença e metafísica: ensaios sobre a desconstrução. Porto Alegre: Edipucrs.

1 “O que indicamos ontologicamente com o termo dis-posição é, onticamente, o mais conhecido e o mais cotidiano, a saber, o humor, o estado de humor” (Heidegger, 1927/1993, p. 188).

Marcelo Vial Roehe, mestre em Psicologia pela Pontifícia Universidade Católica do Rio Grande do Sul, é professor na Universidade Regional Integrada do Alto Uruguai e das Missões, Campus Frederico Westphalen, Rio Grande do Sul. Endereço para correspondência: Rua Caiapó, 120; Porto Alegre, RS; CEP 91900-550. Email:mvroehe@ibest.com.br 